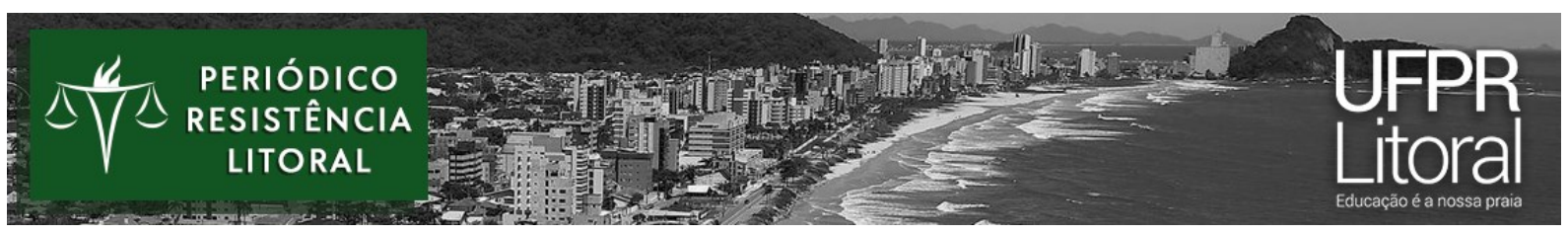

\title{
VELHICE, POLÍTICA DE ASSISTÊNCIA SOCIAL E O TRABALHO DE ASSISTENTES SOCIAIS: Debates e Desafios
}

\author{
Tânia Mara da Silva Backschat ${ }^{1}-$ UEL \\ Joyde Regina Mendes Lone ${ }^{2}-$ UEL \\ Ediane de Paula Machado Soares ${ }^{3}-$ UEL \\ Mabel Mascarenhas Torres ${ }^{4}-$ UEL
}

\begin{abstract}
RESUMO
A pandemia de covid-19 impactou significativamente o modo de vida de todas as pessoas, mas, principalmente, a do idoso. Além de ser considerado parte integrante do grupo de risco, tanto a convivência familiar, como a social foram diretamente impactadas a partir da adoção das medidas de isolamento como precaução de contágio. $\mathrm{O}$ artigo tem como objetivo tecer aproximações sobre a configuração das políticas sociais voltadas à população idosa e as repercussões no trabalho de assistentes sociais, no contexto de pandemia. A discussão apresentada sobre a atual configuração das políticas sociais voltadas à população idosa, especialmente, na política de assistência social, foi construída a partir de pesquisa bibliográfica e documental, enfatizando os atos normativos do SUAS estabelecidos em tempos de pandemia. Os resultados apontam que, embora a Constituição Federal de 1988 considere o idoso como sujeito de direitos, é necessário discutir o exercício desses direitos, e a relação assimétrica entre o Estado e a família, destacando a descontinuidade da oferta de serviços socioassistenciais, a sobrecarga nos cuidados familiares e as alterações no modo como o investimento público é normatizado em decorrência do contexto pandêmico e, as repercussões no trabalho do/a assistente social no contexto de pandemia.
\end{abstract}

Palavras-chave: Envelhecimento. Pandemia. Política de assistência social. Trabalho do/a assistente social.

\section{VEJEZ, POLÍTICA DE ASISTENCIA SOCIAL Y LA LABOR DE LOS TRABAJADORES SOCIALES: Debates y Retos}

RESUMEN: La pandemia de COVID-19 afectó significativamente la forma de vida de todas las personas, pero especialmente de los ancianos. Además de ser considerados parte integrante

\footnotetext{
1 - Assistente social. Doutoranda em Serviço Social e Política Social, Mestre em Serviço Social e Política Social e Graduação em Serviço Social pela Universidade Estadual de Londrina - e-mail: taniamaraback@hotmail.com

2 - Assistente Social. Mestranda em Serviço Social e Política Social, graduação em Serviço Social pela Universidade Estadual de Londrina - e-mail: joyderegina@gmail.com .

3 - Assistente social. Mestranda em Serviço Social e Politica Social, graduação em Serviço Social pela Universidade Estadual de Londrina - e-mail: ediane.de.paula@gmail.com.

4 - Assistente social, doutora em Serviço Social, docente da Universidade Estadual de Londrina - e-mail: mmtorres@uel.br
}

Revista Resistência Litoral (Matinhos PR), Vol. 1 N. 1 p. 89 - 114, jan/jun de 2022. ISSN: 2764-3174 DOI: $\underline{\text { http://dx.doi.org/10.5380/rrl.v1i1.82555 }}$

Direitos Autorais: https://creativecommons.org/licenses/by/4.0/deed.pt_BR 


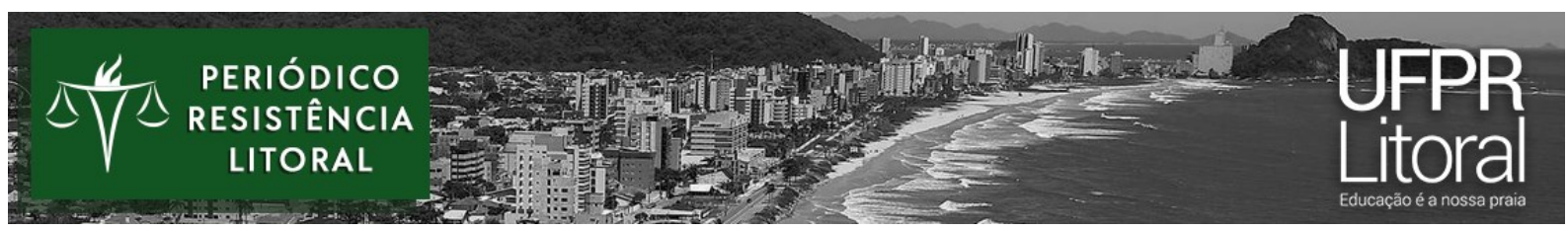

del grupo de riesgo, tanto la vida familiar como la social se vieron directamente impactadas por la adopción de medidas de aislamiento como precaución contra el contagio. Este artículo se construyó a partir de una investigación bibliográfica y documental, presentando reflexiones sobre la configuración actual de las políticas sociales dirigidas a la población anciana, especialmente en la política asistencial. También enfatiza las repercusiones sobre la labor del trabajador social en el contexto de una pandemia. Los resultados muestran que, si bien la Constitución Federal (1988) considera a las personas mayores como sujeto de derechos, es necesario discutir el ejercicio de estos derechos, y la relación asimétrica entre el Estado y la familia, destacando la discontinuidad en la prestación de servicios de asistencia social, la sobrecarga en el cuidado familiar y cambios en la forma de regular la inversión pública como consecuencia del contexto pandémico.

Palabras-clave: Trabajo social. Envejecimiento. Derechos. Pandemia. Política de asistencia social. Labor del trabajador social.

\section{INTRODUÇÃO}

Nascer, viver e envelhecer: mais do que percurso natural da vida, é um processo inserido em relações econômicas e sociais e de acesso aos direitos de cidadania. O envelhecimento populacional tem sido crescente tanto pelos avanços tecnológicos, quanto científicos, aumentando a expectativa de vida ainda que, na sociabilidade do capital, o acesso a melhores condições de vida não repercuta de forma igualitária para todas as pessoas. Assim, a discussão sobre a velhice tem se configurado como um tema relevante para estudos e para a necessidade de elaboração de políticas sociais, tendo em vista a transição demográfica, evidenciando-se o aumento da população. É preciso sinalizar que discutir velhice não pode vir dissociado do debate sobre processos de envelhecimento na sociedade do capital. Sob esse ponto de vista, torna-se essencial a construção de uma análise referenciada nas relações desiguais e hierarquizadas entre as classes sociais, e nas relações de gênero e etnia que fundam o capitalismo. Nesse sentido, os processos de envelhecimento são multidimensionais e expressam as contradições presentes no capitalismo. Sendo assim, é factível afirmar que nos deparamos com idosos que vivem em condições de manter suas necessidades e outros vivem em condição de pobreza. O Estado brasileiro, ao longo do século $\mathrm{XX}$, promulgaria um conjunto de legislações, disseminando a perspectiva da velhice associada a direitos, trazendo a tona o debate em torno da necessidade de consolidação de políticas sociais para esse segmento etário. A Constituição Federal de 1988 inaugura um importante processo de reconhecimento do idoso como sujeito de direito e, nos anos seguintes à sua promulgação, haveria a criação de outras 
legislações exclusivas e correlatas que asseguram os direitos da pessoa idosa, especialmente, nas áreas da saúde, previdência, assistência social, e de legislações que nortearam as determinações das políticas exclusivas para a população idosa.

Pensar em políticas para idosos é considerar os determinantes sócio-históricos que interferem diretamente nos processos de envelhecimento. Destaca-se que a finalidade das referidas políticas é contribuir para a proteção da velhice, especialmente, no tocante aos direitos que possam contribuir para o envelhecimento com preservação da autonomia.

O envelhecimento populacional é uma realidade presente na sociedade brasileira. Portanto, tratar do assunto se faz necessário, tanto para o processo de elaboração e execução das políticas sociais, quanto para a atuação profissional nos contextos em que se insere o atendimento à pessoa idosa. Nessa perspectiva, o presente trabalho tem como objetivo tecer aproximações iniciais sobre a configuração das políticas sociais voltadas à população idosa e as repercussões no trabalho de assistentes sociais, no contexto da pandemia de covid-19, particularizando a política de assistência social. Convém mencionar ainda que este estudo faz parte das investigações sobre o trabalho do/a assistente social, desenvolvidas pelas pesquisadoras junto ao Grupo de Estudo dos Fundamentos e Trabalho de Assistentes Sociais GEFTAS.

O artigo é estruturado em três partes: na primeira parte, foi apresentada uma discussão sobre o significado de velhice, os processos de envelhecimento e os direitos dessa população na sociedade contemporânea; na segunda parte, construída a partir de uma pesquisa documental, foram analisados os principais atos normativos que regulam o atendimento ao idoso na política de assistência social - PAS, com o objetivo de identificar as alterações impostas em decorrência do cenário pandêmico da covid-19, desde as alterações identificadas nos atendimentos e acompanhamento aos idosos, às alterações nas rotinas e cotidiano daqueles que trabalham nessa política, bem como alterações nas estratégias, recursos e acesso aos serviços pelos idosos e seus familiares; por fim, segue-se uma reflexão sobre as perspectivas e desafios para o atendimento ao idoso, a partir das contribuições que os assistentes sociais podem trazer para análise e intervenção com a população idosa.

\section{O ENVELHECIMENTO PARA A SOCIEDADE CONTEMPORÂNEA}

As pessoas estão vivendo mais e o prolongamento da duração da vida começou a ser percebido a partir da metade do século XX. Para as autoras Camarano, Kanso e Mello (2004), 


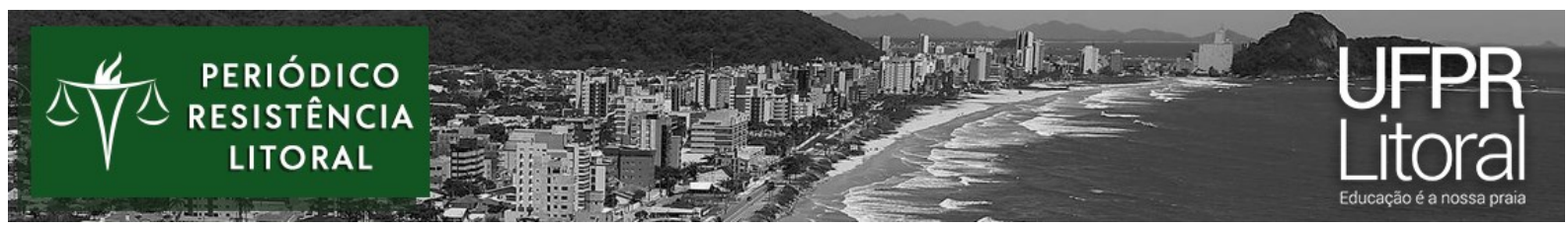

a partir de 1940, houve significativo crescimento populacional, destacando-se a ampliação do número de idosos. A observação das autoras indica a associação do aumento da população idosa a: longevidade, acesso à saúde e a serviços socioassistenciais de caráter protetivo, desenvolvimento tecnológico, diminuição da natalidade, entre outros.

O aumento da longevidade no Brasil traz consigo a necessidade premente de pensar que a desigualdade constitutiva da sociedade do capital afeta decisivamente os processos de envelhecimento, sobretudo, do idoso pobre, em função, muitas vezes, das precárias condições de vida e trabalho. Desse modo, é necessário reforçar a heterogeneidade das experiências do envelhecimento, reconhecendo que tal processo não é igual para todos os idosos, como reafirma Costa (2019, p. 99), “[...] haja vista que as condições de vida são determinadas pela inserção precária ou não no mundo do trabalho, que condiciona o sujeito, define o 'seu' lócus social e até mesmo o acesso aos seus direitos humanos e sociais".

A condição de classe dos idosos é peremptória para entender como se dá a velhice no Brasil. Nesse sentido, no envelhecimento do trabalhador, são experienciadas novamente as desigualdades outrora vivenciadas, mas, nesse momento da vida potencializado por gastos além dos fundamentais (alimentação, moradia, etc.) em função do surgimento de doenças, remédios e despesas com filhos e netos, que podem sobreviver de sua renda.

A velhice e os processos de envelhecimento são estudados a partir de diversas perspectivas, no entanto, a gerontologia crítica vai no caminho de contribuir com esse modo de analisar o envelhecimento, indicando que a condição da classe trabalhadora na sociedade do capital, as diferenças socioeconômicas, o acesso ao trabalho e as políticas sociais irão determinar a forma como a velhice será vivenciada.

Do mesmo modo, Teixeira (2017) considera o envelhecimento e a velhice como fases da vida, sendo processos biopsicossociais associados a condições socioeconômica, psicológica e genético-biológica. Sendo o envelhecimento do trabalhador uma expressão da questão social, a autora aponta que "os trabalhadores idosos e suas condições de vida é que têm centralidade na configuração do envelhecimento como problema social” (TEIXEIRA, 2017, p. 34). Assim, é atribuído à classe social o fator relevante na diferenciação do envelhecimento da mesma forma que o homogeneíza.

Os estudos sobre a temática apontam que a velhice é experienciada de forma distinta, podendo o velho vivenciá-la de forma independente e/ou tornando-se dependente de cuidados 
devido, entre outros fatores, às relações precarizadas e pauperizadas de trabalho, e à inequidade de acesso aos direitos previstos nas legislações.

Daí a importância de refletir sobre o significado de tornar-se velho na sociedade capitalista. Ao pensar na velhice, é comum associá-la à idade ou a conceitos equivocados como de velhos cansados, decrépitos, dependente de cuidados, além de temê-la ou ter uma ideia pejorativa, frequentemente, com uma imagem de uma pessoa velha encurvada e até necessitando do uso de bengala, ou, por vezes, aquele que será um custo ao sistema no que diz respeito ao pagamento de aposentadorias, pensões e benefícios, desconsiderando toda a trajetória de trabalho e expropriação vivenciada até ali. Ademais, no sistema capitalista, o trabalhador é visto segundo o seu potencial de venda da força de trabalho, logo, ao reduzir sua produção e, ou até mesmo perder as capacidades de trabalho, esse trabalhador perde a sua importância para o trabalho. Apesar de as pessoas estarem vivendo mais em função dos fatores supramencionados e de o envelhecimento ser um processo heterogêneo, esse tipo de entendimento ainda é muito comum.

Considerando a importância dessa temática, no Brasil, posteriormente à Constituição Federal de 1988, o Estatuto do Idoso (2003) considera idosa a pessoa com sessenta anos ou mais. Entretanto, há o entendimento de que somente a idade não pode ser o único fator a ser avaliado na classificação do velho, tampouco pode prevalecer a compreensão de que só existe um tipo de velhice e todas as pessoas irão envelhecer da mesma maneira. Por isso, o marco legal previsto pelo Estatuto do Idoso é de extrema relevância para o entendimento de que o idoso é sujeito de direitos e necessita de proteção do Estado e das políticas sociais.

Para Simone de Beauvoir (2018), o envelhecimento deve ser abordado tanto pelo aspecto biológico, como pelo cultural, psicológico e social. A autora apresenta, de forma detalhada, as mudanças biológicas provocadas pelo envelhecimento e suas consequências em várias culturas. Chama a atenção pela diferença entre o envelhecer masculino e o feminino, uma vez que as relações sociais resultam de uma história de convivência, podendo, nessa etapa da vida, consistir-se de afeto e acolhida ou desapreço e solidão.

Além disso, Beauvoir (2018) ressalta que a pobreza potencializa as precariedades ensejadas pelo envelhecimento, sendo o velho útil na medida em que conserva suas capacidades funcionais, deixando, dessa forma, de ser útil para o capital diante da perda do uso de sua força de trabalho. Apesar dessas conclusões, destaca que a "Bela Velhice" consiste em que o homem 


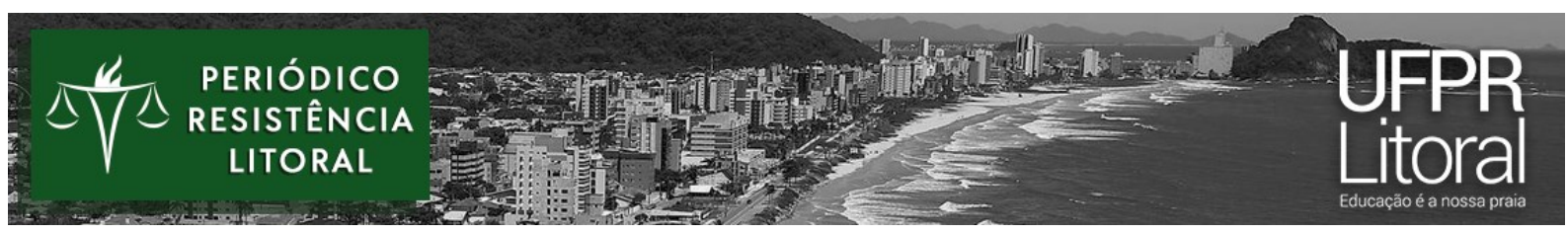

descobriu, nessa etapa da vida, seu equilíbrio moral e físico, não como um jovem, mas a partir das possibilidades da velhice. Para Costa (2017, p. 141),

O processo de envelhecimento e velhice é heterogêneo, multifacetado e complexo, pois se constrói e se (re)significa sobre o embate de classes, ou seja, o processo de envelhecimento - que se dá ao longo da vida humana - e a velhice são construções sociais, consequentemente, vêm permeados de valores que são condicionados pelo tempo e espaço do capital.

Entretanto, é preciso se atentar ao fato de que o envelhecimento se inicia no momento do nascimento, e as vivências em cada etapa da vida, ou seja, nas fases da infância, juventude e vida adulta, irão definir a forma como será experienciada a velhice. Em outras palavras, o acesso à educação, o cuidado com a saúde, as relações familiares e comunitárias, a questão de gênero, bem como o acesso ou não ao mercado formal e informal de trabalho, e as condições de trabalho, entre outros fatores, poderão determinar a condição de como será vivenciada a velhice.

Com isso, a finalidade é apontar que há idosos que manterão a independência para a realização do autocuidado e do próprio sustento, bem como aqueles que irão apresentar comprometimento de sua capacidade para a realização das atividades da vida diária ${ }^{5}$ e as atividades instrumentais ${ }^{6}$ do cotidiano. Cabe destacar que há vários graus de dependência apresentados pelos idosos, além da mudança no paradigma destes. Em outras palavras, a vivência da velhice do século XX é diferente da do século XXI.

Em virtude do mencionado, torna-se imperioso refletir acerca das condições objetivas de vida dos idosos. Certamente o Brasil, que era conhecido por ser um país de jovens, em função do aceleramento do processo de envelhecimento, passa a contar com número significativo de idosos. Atualmente, segundo o Instituto Brasileiro de Geografia e Estatística - IBGE (2020), a expectativa de vida aumentou, em média, para 76,6 anos, aumentando cerca de 31,1 anos, quando comparada com a década de 1940. Inclusive, observa-se que o número populacional

\footnotetext{
${ }^{5}$ De acordo com o Caderno de Atenção Básica e Envelhecimento da Pessoa Idosa (2006), as atividades da vida diária estão relacionadas ao autocuidado, a exemplo de alimentar-se, banhar-se, vestir-se, mobilizar-se, ir ao banheiro, deambular e manter o controle sobre suas necessidades fisiológicas. (CADERNO DE ATENÇÃO BÁSICA: ENVELHECIMENTO E SAÚDE DA PESSOA IDOSA, 2006, p.37).

${ }^{6}$ As atividades instrumentais da vida diária estão associadas à participação do idoso em seu entorno social e demonstra a capacidade de uma pessoa em levar uma vida independente dentro de uma comunidade, ou seja: utilizar meios de transporte, manipular medicamentos, realizar compras, realizar tarefas domésticas leves e pesadas, utilizar o telefone, preparar refeições e cuidar das próprias finanças. (CADERNO DE ATENÇÃO BÁSICA: ENVELHECIMENTO E SAÚDE DA PESSOA IDOSA, 2006, p.37).
} 


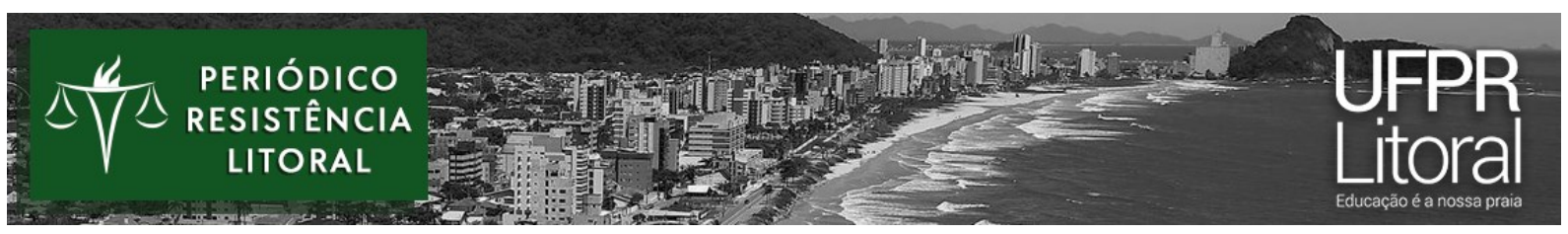

das pessoas com mais de oitenta anos também tem crescido substancialmente. Em relação ao gênero, nota-se que a velhice é feminina, sendo, em média, sete anos acima dos homens.

Segundo dados do Conselho Estadual dos Direitos do Idoso do Paraná - CEDI (2021),

O Estado do Paraná segue o mesmo padrão acelerado de envelhecimento populacional. O último Censo do IBGE (2010) indica que o Estado tem 1.316.554 de habitantes com mais de 60 anos, representando 11,2\% da população paranaense total. Assim, o processo de envelhecimento pelo qual passa a população brasileira nos conduz a fortalecer, com a máxima agilidade, políticas públicas de proteção e promoção dos direitos da pessoa idosa. (CEDI, 2021, s/d, n.p)

Esses dados só demonstram a necessidade de maiores investimentos e discussões quanto à temática do envelhecimento na sociedade e de trazer à tona como estão vivendo os idosos, principalmente, no estado do Paraná. Pensando nesse enfrentamento, criou-se, através da Lei n. ${ }^{\circ} 11863 / 1997$, a Política Estadual dos Direitos da Pessoa Idosa, que traz as responsabilidades de assegurar os direitos do idoso no estado do Paraná.

Mas o que significa viver por mais tempo, sobretudo, no contexto de uma das maiores crises de saúde nesse solo? A pandemia escancarou as dificuldades do Estado em garantir direitos e proteção. Pensar sobre o assunto nos remete a considerar a pessoa idosa como sujeito de direitos, dessa forma, tendo o reconhecimento de suas capacidades e funcionalidades, o que lhe permite, desde que esteja lúcido, tomar decisões. Outra situação importante a ser considerada consiste na necessidade da transversalidade e da intersetorialidade das políticas públicas nas discussões das ações em relação à pessoa idosa.

Seguindo nessa perspectiva, de considerar o velho como sujeito de direitos, é oportuno ressaltar a Constituição Federal de 1988, que, ao tratar do envelhecimento, atribui à família, à sociedade e ao Estado o dever de prestar assistência às pessoas idosas. Dessa Lei maior, derivaram outras normativas exclusivas e correlatas, discutidas ao longo deste artigo, cujo objetivo consiste em assegurar que a pessoa idosa possa desfrutar de um envelhecimento protegido, de modo a ter preservados a saúde física e mental e o aperfeiçoamento moral, intelectual, espiritual e social, em condições de liberdade e dignidade (BRASIL, 2003).

Em virtude do mencionado, o atendimento dos direitos dos velhos deve ser assegurado tanto pela família, como pela sociedade e pelo Estado. Com isso, é a intenção deste trabalho chamar a atenção para o compartilhamento dessa responsabilidade pelas três instâncias, mas na perspectiva de que a criação e a condução das políticas públicas devem ser realizadas pelo Estado, em conformidade com as particularidades da realidade brasileira, historicamente marcada pelas desigualdades sociais, sobretudo, do trabalhador, que, ao envelhecer sob 


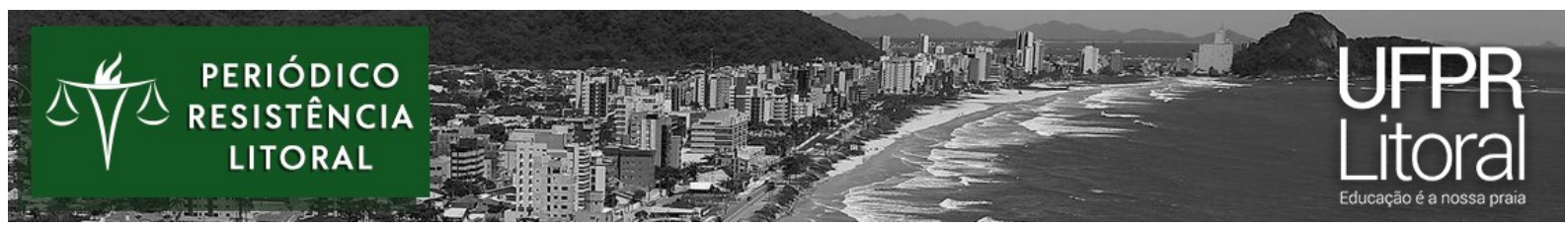

determinadas condições de vida e nas relações de produção e reprodução social, vivenciará diversidades e desigualdades no envelhecimento.

Diante disso, torna-se premente falar sobre o envelhecimento, tanto para informar a população em geral, de modo a desconstruir os conceitos equivocados sobre a velhice, como para contribuir na valorização do velho e na criação de políticas públicas intersetoriais que satisfaçam suas necessidades, considerando as diferentes velhices. Igualmente, é fundamental ressaltar ser nessa etapa da vida que as desigualdades se acentuam, em razão de deteriorações físicas, orgânicas e fisiológicas, com maior ocorrência de doenças, complicações funcionais, além de "degradações sociais, rebaixamento das necessidades sociais, dependência dos recursos públicos ou assistência privada" (TEIXEIRA, 2017, p.41).

Em função dessa diversidade e da desigualdade socioeconômica no envelhecimento, é urgente situar as demandas impostas pela velhice, sobretudo, da classe trabalhadora, para que o Estado possa atender os direitos da pessoa idosa, por meio da criação de políticas sociais articuladas e coletivas, regidas pelos princípios de universalidade e redistributividade, de modo a alcançar, principalmente, o objetivo de oferecer a devida proteção ao velho brasileiro.

Nesse sentido, explanaremos sobre as principais as legislações asseguradas a esse segmento, os desafios de sua execução no contexto de pandemia da covid-19 e as garantias de direitos e proteção a essa população, previstos nas políticas públicas.

\section{ATOS NORMATIVOS QUE REGULAM O ATENDIMENTO AO IDOSO NA POLÍTICA DE ASSISTÊNCIA SOCIAL}

A aprovação da Constituição Federal de 1988 é um marco significativo no reconhecimento legal da proteção social enquanto papel do Estado no campo das políticas sociais. A Carta Constitucional assegura novas bases para o sistema de proteção social brasileiro, como a

[...] centralidade da responsabilização do Estado na regulação, normatização, proposição e implementação de políticas públicas no âmbito da proteção social; a proposta da descentralização e participação da sociedade no controle das políticas sociais (YASBEK, 2018, p. 99).

A partir de então, aos brasileiros são assegurados novos direitos, dentre eles, os vinculados à Seguridade Social: um conjunto integrado de ações dos poderes públicos e da sociedade é destinado a assegurar direitos relativos a saúde, previdência social e assistência 


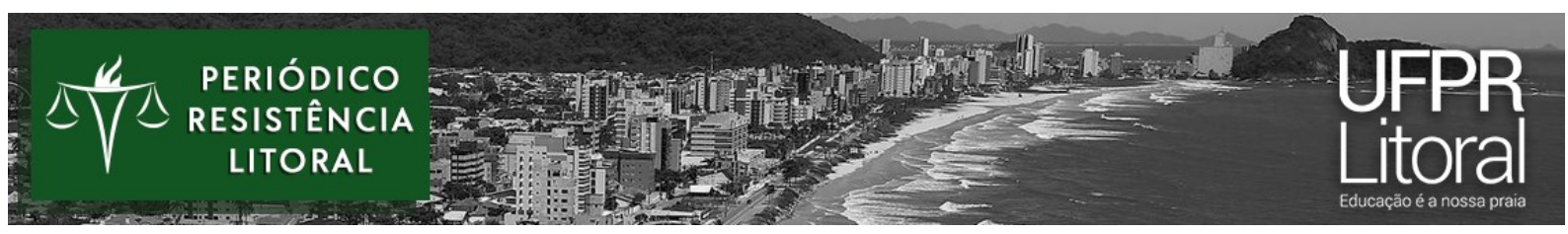

social. Com isso, a velhice começou a ser reconhecida enquanto lugar de cuidado e proteção com responsabilizações, garantidos pela família, comunidade, sociedade e poder público.

Desse modo, na década seguinte, várias legislações referentes às políticas setoriais, que incluíram a proteção aos idosos, foram implementadas. Ainda na década de 1990, observamos que a Lei Orgânica da Assistência Social - Lei n. ${ }^{\circ}$ 8.742, de 7 de dezembro de 1993, estabeleceu programas e projetos de atenção ao idoso, em corresponsabilidade nas três esferas de governo, e regulamentou a concessão do Benefício de Prestação Continuada, previsto no art. 203 do texto constitucional. Esse benefício vem garantir os direitos sociais básicos do idoso e da pessoa com deficiência, por meio da transferência de renda para famílias sem condições de prover a manutenção da vida.

Dando prosseguimento às diretrizes lançadas pela Constituição, foi aprovada, em 1994, pela Lei n. ${ }^{\circ} 8.842$, de 4 de janeiro de 1994, a Política Nacional do Idoso, a fim de assegurar direitos sociais ao idoso, criando condições de promoção da sua autonomia, integração e participação efetiva na sociedade. Por meio dessa legislação foi criado, ainda, o Conselho Nacional do Idoso, implementado, entretanto, apenas em 2002.

$\mathrm{Na}$ década de 2000, é sancionado o Estatuto do Idoso, pela Lei n. ${ }^{\circ} 10.741$, de $1^{\mathrm{o}}$ de outubro de 2003, destinado a assegurar aos idosos os direitos fundamentais à pessoa humana, estabelecendo, ser uma

[...] obrigação da família, da comunidade, da sociedade e do Poder Público assegurar ao idoso, com absoluta prioridade, a efetivação do direito à vida, à saúde, à alimentação, à educação, à cultura, ao esporte, ao lazer, ao trabalho, à cidadania, à liberdade, à dignidade, ao respeito e à convivência familiar e comunitária. (BRASIL, 2003, art. $3^{\circ}$ )

A família ocupa um lugar de centralidade na proteção e nos cuidados em relação à pessoa idosa e, quando não consegue exercer essa função, a sociedade e o poder público devem assegurar condições de vida e envelhecimento de modo saudável e digno. Nesse sentido, nos marcos dos atos normativos federais, as políticas sociais são pensadas como um conjunto articulado de ações governamentais e não governamentais, por meio de uma rede de atendimento no âmbito das políticas setoriais. Tendo este artigo como foco de discussão a política de assistência social, podemos elencar a

Política Nacional de Assistência Social (PNAS/04), que reafirma o caráter protetivo da assistência social, conforme previsão constitucional, e preconiza o fortalecimento de vínculos como um dos objetivos na prestação de serviços, considerando processos que vulnerabilizam indivíduos e famílias, os quais podem ensejar violações de 


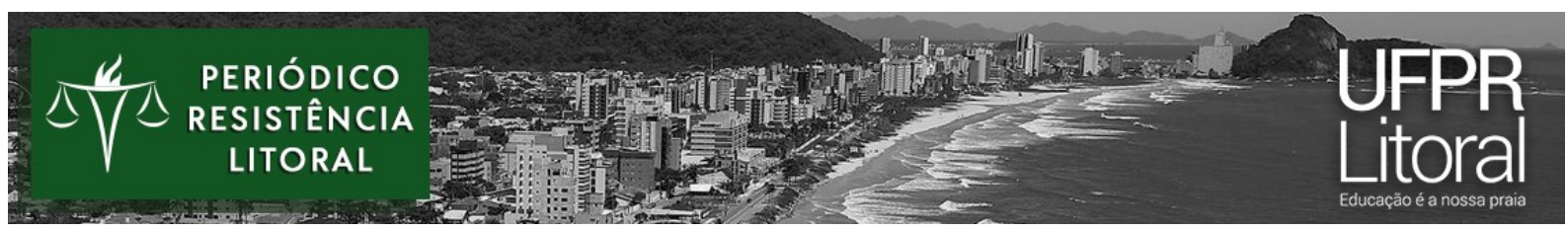

direitos, caracterizadas na PNAS como situações de risco pessoal e social. (SILVEIRA, 2017, p. 496)

Igualmente, as Normas Operacionais Básicas delinearam a construção de um Sistema Único de Assistência Social - SUAS, nos níveis de Proteção Social Básica - PSB e Proteção Social Especial - PSE, e a estruturação dos recursos humanos para a operacionalização dessa política, reafirmando a necessidade de organização do SUAS em cada âmbito, a partir de prioridades e metas, com garantia de previsões anteriores, a saber, comando único, conselho, plano e fundo. Por fim, em relação à Tipificação Nacional dos Serviços Socioassistenciais, aprovada pela Resolução n. ${ }^{\circ} 109$ de 11 de novembro de 2009 do Conselho Nacional de Assistência Social - CNAS, encontramos a organização dos serviços socioassistenciais, articulados com a oferta dos programas, projetos e benefícios socioassistenciais.

De acordo com as Proteções Sociais por níveis de complexidade do SUAS, os Serviços de Proteção Social Básica são ofertados com a finalidade de prevenir situações de risco, destinados à população que vive em situação de vulnerabilidade social decorrente de pobreza, privação ou fragilização de vínculos afetivos relacionais e de pertencimento social. Os programas e projetos são executados por meio do Serviço de Proteção e Atendimento Integral à Família - PAIF, voltados a integralidade e fortalecimento do papel protetivo da família; do Serviço de Convivência e Fortalecimento de Vínculos - SCFV, de papel complementar ao trabalho social com as famílias, executado de maneira geracional para os membros das famílias; e do Serviço de Proteção Social Básica, no domicílio, para pessoas com deficiência e idosas, com a finalidade de prevenção de agravos que possam provocar rompimentos de vínculos familiares e sociais. Nesses dois últimos serviços, executam-se as ações estratégicas de atendimento a segmentos etários, tais como, as pessoas idosas, contribuindo para a construção de contextos mais inclusivos.

Os Serviços de Proteção Social Especial são uma

[...] modalidade de atendimento assistencial destinada a famílias e indivíduos que se encontram em situação de risco pessoal e social, por ocorrência de abandono, maustratos físicos e/ou psíquicos, abuso sexual, uso de substâncias psicoativas, cumprimento de medidas socioeducativas, situação de rua, situação de trabalho infantil, entre outras. (PNAS, 2004, p. 31)

Os serviços se subdividem em duas complexidades, a saber na Média Complexidade, são realizadas ações especializadas e continuadas às famílias e aos indivíduos quando os direitos foram ameaçados ou violados, mas os vínculos familiares e comunitários ainda não 
foram rompidos. Assim, são realizados acompanhamentos sistemáticos e monitorados por meio do Serviço de Proteção e Atendimento Especializado a Famílias e Indivíduos - PAEFI, caracterizado por ações de apoio, orientação e acompanhamento a famílias com um ou mais de seus membros em situação de ameaça de direitos; do Serviço Especializado em Abordagem Social que, de forma continuada, tem a finalidade de assegurar o trabalho social de abordagem social nos territórios, no referente a trabalho infantil, exploração sexual de crianças e adolescentes e situação de rua; do Serviço de Proteção Social a Adolescentes em Cumprimento de Medida Socioeducativa de Liberdade Assistida - LA, e de Prestação de Serviços à Comunidade - PSC, que são voltados para atenção socioassistencial e acompanhamento de adolescentes e jovens em cumprimento de medidas socioeducativas determinadas judicialmente; do Serviço Especializado para Pessoas em Situação de Rua, ofertado para pessoas que utilizam as ruas como espaços de moradia e/ou sobrevivência; e do Serviço de Proteção Social Especial para Pessoas com Deficiência, Idosos(as) e suas Famílias com membros familiares com algum grau de dependência e que tiveram suas limitações agravadas por situações de violência.

Observa-se que, na Média Complexidade, as ações estratégicas de atenção à população idosa se voltam para esse serviço especializado cuja finalidade é a diminuição da exclusão social tanto do dependente, como do cuidador, dado que o cuidado com pessoas em situação de dependência pode ser prolongado. Quando da ocorrência de situações de vulnerabilidades, deve ser viabilizado o acesso a benefícios, serviços de políticas públicas setoriais e inclusão nos programas de transferência de renda, e, quando constatada situação de violência e risco pessoal à pessoa idosa, pode haver o encaminhamento para serviços de acolhimento institucional.

Os Serviços de Alta Complexidade garantem a proteção integral, por meio da oferta de moradia, alimentação e higienização, a família e indivíduos que se encontram com direitos violados e necessitam ser retirados do seu núcleo familiar ou comunitário. As ações para esse público são ofertadas por meio do Serviço de Acolhimento Institucional, nas seguintes modalidades: abrigo institucional; Casa-Lar; Casa de Passagem com especificações para públicos como crianças e adolescentes, adultos e famílias, mulheres em situação de violência, jovens e adultos, e idosos; Serviço de Acolhimento em República para a oferta de proteção, apoio e moradia subsidiada, prioritariamente, para jovens; Serviço de Acolhimento em Família Acolhedora voltado para crianças e adolescentes cujas famílias estejam impedidas de exercer sua função de cuidado e proteção; Serviço de Proteção em Situações de Calamidades Públicas 
e de Emergências, que promove apoio e proteção à população atingida por situações de emergência e calamidade pública, com a oferta de alojamentos provisórios e provisões materiais, conforme as necessidades apresentadas.

Esse conjunto de diferentes serviços, seja na modalidade de Proteção Social Básica, seja na Proteção Social Especial, requer que as ações da política de assistência social sejam ofertadas de forma a garantir as seguranças afiançadas pelo SUAS. A Segurança de Acolhida envolve ter acolhidas suas demandas e seus interesses, por exemplo, acesso às provisões de necessidades básicas; além de receber orientações e encaminhamentos, visando o acesso a benefícios, programas de transferência de renda e demais serviços socioassistenciais (quando necessário), resguardando identidade, integridade e história de vida dos beneficiários. Na Segurança de Desenvolvimento da Autonomia, elencam-se as vivências de experiências pautadas pelo respeito a si próprio e aos outros, emitindo a sua opinião e fazendo suas próprias escolhas, fundamentadas em princípios ético-políticos de defesa da cidadania e justiça social, potencializadoras da participação cidadã, inclusive, com o desenvolvimento do universo informacional e cultural, utilizando-se, para isso, de recursos disponíveis na comunidade.

A Segurança de Convívio Familiar e Comunitário visa proporcionar aos sujeitos vivenciar experiências que contribuam para o estabelecimento e fortalecimento de vínculos familiares e comunitários; ampliar a capacidade protetiva das famílias e a superação das fragilidades sociais, além de ter acesso a serviços e ações intersetoriais para a solução da situação enfrentada, tais como, abrigo, alimentação, saúde e moradia, dentre outras necessidades. Finalmente, há a Segurança de Sobrevivência (rendimento e autonomia), que envolve ações, tais como, ser socorrido em situações de emergência e calamidade pública.

Portanto, na execução dos serviços socioassistenciais, é necessário o desenvolvimento de um trabalho social voltado para orientação sociofamiliar, de articulação da rede de serviços e políticas públicas setoriais e de defesa de direitos, articulação interinstitucional com demais órgãos do Sistema de Garantia de Direitos, protocolos de referência e contrarreferência, organização de banco de dados e informações sobre os serviços, assim como um diagnóstico socioterritorial. Isso exige a qualificação das ofertas no âmbito da política de assistência social, requerendo uma equipe de referência com profissionais habilitados sendo necessário, portanto, uma gestão do trabalho como uma questão estratégica na qualidade dos serviços socioassistenciais. 


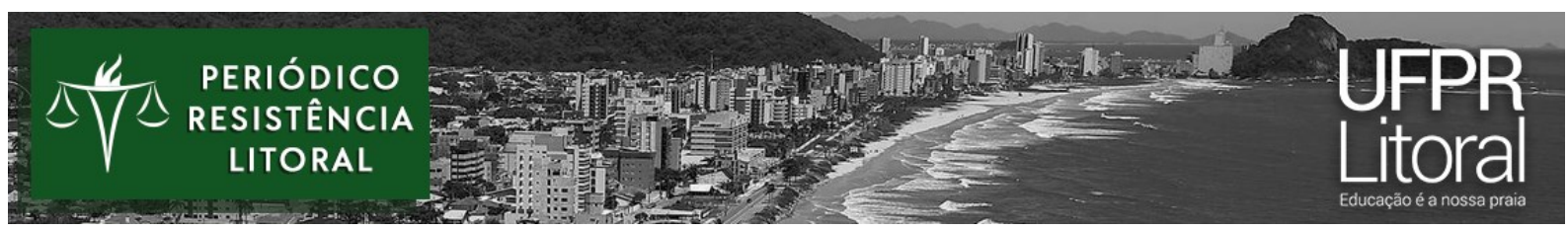

Ante a situação de declaração de estado de calamidade pública decorrente da pandemia de covid-19, em março de 2020, várias recomendações e orientações foram expedidas, tanto por organismos internacionais, quanto órgãos governamentais, em suas diferentes esferas de governo, a fim de prevenir o avanço da disseminação do vírus e proteger os usuários e profissionais que atuam nesses serviços, considerando os riscos de contágio em ambientes de atendimento coletivo.

A política de assistência social é considerada uma das áreas essenciais e indispensáveis ao atendimento das necessidades que colocam em risco a sobrevivência e a segurança da população, conforme Decreto n. ${ }^{\circ} 10.282$ de 20 de março de 2020. No âmbito do Ministério da Cidadania, onde está alocada a Secretaria Nacional de Assistência Social, e no Ministério da Mulher, Família e Direitos Humanos, onde se regulam as ações voltadas ao idoso, várias medidas de recomendação de prevenção ao coronavírus foram expedidas, em dois direcionamentos: uma, alterando rotinas e formas de atendimentos, sendo necessária a atenção ao ambiente, à organização do serviço e aos cuidados com os atendidos, em especial, os grupos vulneráveis, como as pessoas idosas, pessoas com deficiência e pessoas com doenças crônicas, por exemplo, diabetes mellitus, doença cardiovascular, problemas respiratórios, tratamento atual ou recente de câncer e doenças que diminuem a imunidade.

O segundo direcionamento refere-se aos atos normativos que tratam do financiamento dos serviços, uma vez que, decretada situação de emergência e calamidade, conforme o artigo 65 da Lei Complementar n. ${ }^{\circ} 101$ de 04 de maio de 2020 - Lei de Responsabilidade Fiscal, as regras da gestão de recursos públicos são flexibilizadas, de forma a otimizarem a sua utilização, inclusive, com alteração das metas fiscais no exercício, tendo em vista conter os avanços da doença.

Em relação ao primeiro conjunto normativo, destacamos a Portaria Federal n. ${ }^{\circ}$ 337/2020 de 24 de março de 2020 e a Portaria n. ${ }^{\circ} 100$ de 14 de julho de 2020, bem como os informes e documentos normativos, que recomendam o funcionamento da rede socioassistencial de Proteção Social Básica e de Proteção Social Especial de Média Complexidade do SUAS, de modo a assegurar a manutenção da oferta do atendimento à população nos diferentes cenários epidemiológicos da pandemia causada pelo vírus Sars-CoV-2. Com isso, os municípios se viram impelidos a reorganizar suas ofertas, programas e benefícios socioassistenciais àqueles que necessitarem, observando as medidas e as condições de segurança e saúde dos usuários e profissionais do SUAS. 


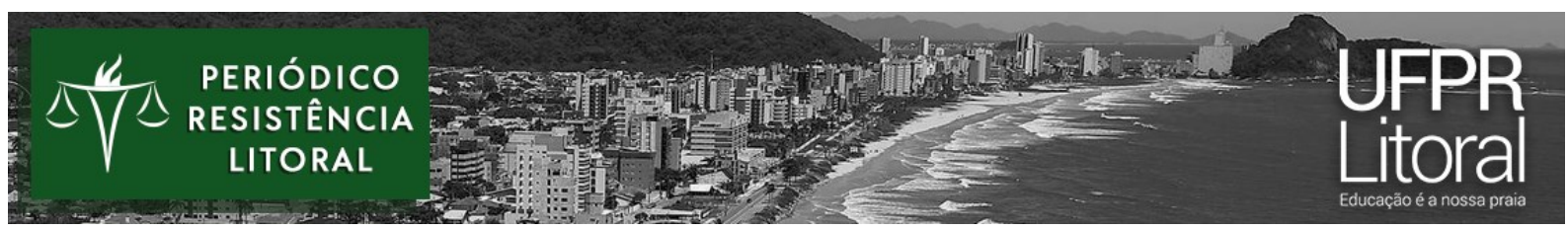

De acordo com o art. $3^{\circ}$ da Portaria n. ${ }^{\circ}$ 337/2020, são consideradas medidas de prevenção, cautela e redução do risco de transmissão, de maneira a preservar a oferta regular e essencial dos serviços, programas e benefícios socioassistenciais:

I - adoção de regime de jornada em turnos de revezamento em que se promova melhor distribuição da força de trabalho com o objetivo de evitar a concentração e a proximidade de pessoas no ambiente de trabalho;

II - adoção de medidas de segurança para os profissionais do SUAS com a disponibilização de materiais de higiene e Equipamentos de Proteção Individual - EPI, recomendados pelo Ministério da Saúde, afastamento ou colocação em teletrabalho dos grupos de risco;

$[\ldots]$

IV - flexibilização as atividades presenciais dos usuários no âmbito dos Centros de Referência da Assistência Social - CRAS e dos Centros Especializados de Assistência Social - CREAS, com vistas a reduzir a circulação de pessoas e evitar a aglomeração nos equipamentos;

$[\ldots]$

VI - organizar a oferta dos serviços, programas e benefícios socioassistenciais preferencialmente por agendamento remoto, priorizando os atendimentos individualizados graves ou urgentes, evitando-se a aglomeração de pessoas nas salas de espera ou recepção das unidades;

VII - realização de atendimentos individuais em ambientes amplos, arejados e constantemente limpos, atentando para a garantia de sigilo e privacidade do atendimento, ainda que se opte por realiza-lo em locais abertos como varandas, quintais, tendas, etc; e

VIII - suspensão temporária de eventos, encontros, cursos de formação, oficinas, entre outras atividades coletivas. (BRASIL, 2020)

Essas são algumas das medidas recomendadas e que alteraram significativamente a rotina dos serviços e o modo como os seus profissionais tiveram de se reorganizar para o atendimento das demandas da população. No âmbito da Proteção Social Básica, a suspensão das atividades dos serviços de convivência de modo presencial afetou diretamente o público atendido, e, no ciclo etário de pessoas acima de sessenta anos, agregou-se o fato de se enquadrarem como grupo de risco prioritário suscetível às formas mais graves do adoecimento pelo novo coronavírus. Para garantir a oferta do serviço no período de pandemia, as ações foram reorganizadas com ênfase no acompanhamento familiar e para indivíduos via aplicativos e redes sociais.

Contudo, o acesso aos recursos tecnológicos não se deu de forma homogênea entre a população, sendo necessário identificar as famílias: com acesso a telefone celular e/ou convencional; com acesso a smartphone e internet; ou sem acesso a ferramentas tecnológicas. Para cada uma dessas situações, é necessária a adoção de metodologia e estratégia de trabalho, recriando e adaptando o trabalho social com famílias, tendo como resultado o aumento do volume de trabalho para as equipes. 


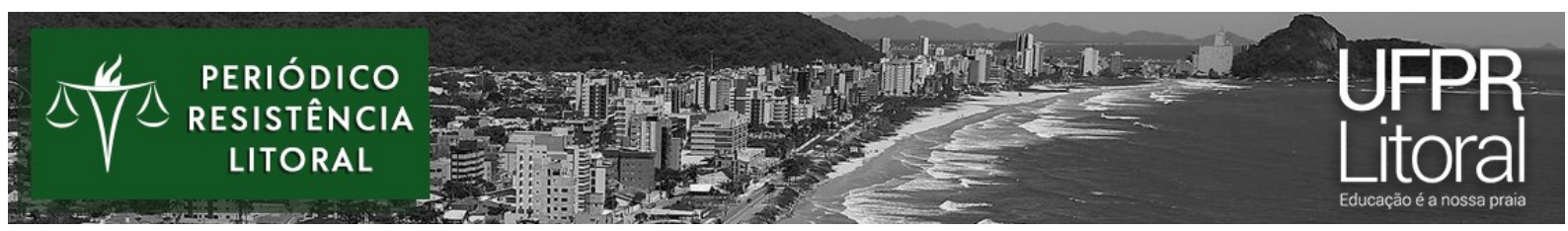

Diante da realidade da pandemia, observa-se, ainda, a intensificação do convívio familiar em âmbito doméstico, evidenciando a importância da atuação das equipes de trabalho do SUAS no campo relacional, uma vez que pode indicar tanto o fortalecimento dos potenciais protetivos, como a intensificação das violações às integridades social e física dos sujeitos. O convívio prolongado no âmbito doméstico por conta do isolamento social, o medo da contaminação e adoecimento pela doença, a incerteza de acesso ao sistema de saúde, perdas e luto de familiares e pessoas próximas, insegurança e insuficiência de recursos para a adequada proteção são alguns dos fatores presentes no convívio familiar com risco de uma sobrecarga emocional, expondo idosos, crianças, adolescentes, mulheres e pessoas com deficiência a uma situação de vulnerabilidade social. Com isso, as suspeitas de ocorrências de violência doméstica, sobrecarga dos cuidadores familiares e conflitos geracionais se intensificaram, demandando a atuação das equipes da Proteção Social Especial.

Quando as suspeitas das violações de direitos são confirmadas e demandam o acolhimento institucional, novos desafios se colocam no atendimento ao idoso, uma vez que as Instituições de Longa Permanência para Idosos - ILPIs se deparam com um expressivo número de contaminações do público acolhido, devido ao alto risco de transmissibilidade da doença e a ausência de estrutura física e humana para o atendimento das demandas.

A continuidade da oferta foi mantida com os cuidados aos idosos acolhidos, porém observaram-se restrições e precauções em relação aos novos acolhimentos, e, mesmo com o plano de contingência, foram mantidos apenas para situações excepcionais. Essa situação perdurou até a cobertura vacinal dos idosos em acolhimentos e dos profissionais das equipes que trabalham nessas instituições, sendo esse público, juntamente com os demais idosos, os primeiros grupos vacinados, conforme o Plano Nacional de Imunização.

Nesse sentido, destaca-se a importância do segundo direcionamento dos atos normativos, relacionados ao financiamento dos serviços. Foi expedida, pelo Ministério da Cidadania, a Portaria n. 369 de 29 de abril de 2020, com a finalidade de repassar recurso federal emergencial a partir de duas categorias, a saber, a estruturação da rede do SUAS e a execução de ações socioassistenciais. A estruturação da rede contemplou ações como a aquisição de EPIs aos trabalhadores do SUAS e de alimentos ricos em proteína para pessoas idosas e pessoas com deficiência atendidas pelos Serviços de Acolhimento Institucional e Centros-Dia. Na segunda categoria, os recursos para ações socioassistenciais foram direcionados à provisão de 


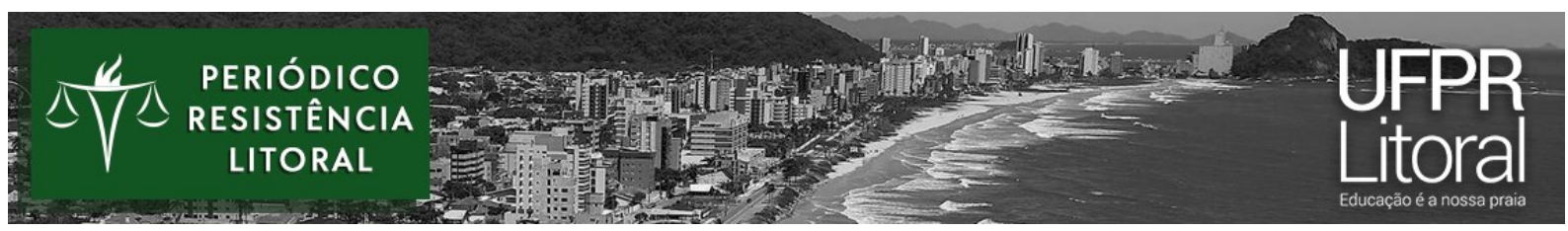

alojamentos, isolamento, dentre outros, a pessoas e/ou famílias em situação de vulnerabilidade e risco social afetadas pela pandemia.

A Portaria n. 378 de 07 de maio de 2020 também teve como finalidade o repasse de recurso financeiro, porém de forma extraordinária, para o incremento temporário na execução das ações socioassistenciais, a fim de garantir a continuidade da prestação dos serviços de forma direta à população mais afetada pelos rebatimentos da pandemia. Nessa última, ocorreu a transferência aos blocos da Proteção Social e Especial, tendo como referência o valor repassado em fevereiro de 2020, permitindo uma maior flexibilidade para o ordenamento das despesas seguindo as regras já existentes. Em ambas as Portarias, os recursos financeiros foram administrados pelo Poder Executivo, quer seja na modalidade direta, de serviços públicos, quanto na modalidade indireta, geridos por organizações da sociedade civil.

No que se refere à Portaria Conjunta n..$^{\circ} 01$ de 02 de abril de 2020, embora esta autorize a utilização dos recursos e, principalmente, dos saldos para as ações de combate à pandemia em qualquer circunstância, inclusive com a contratação de profissionais emergencial e temporariamente, a fim de reforçar as equipes existentes, muitos municípios encontraram dificuldades com a priorização das licitações voltadas para a aquisição de insumos, bens e serviços, assim como de contratação de profissionais, uma vez que os esforços estavam voltados à política de saúde. Ou seja, ainda que a assistência social seja serviço essencial no contexto pandêmico, verifica-se a que a sobreposição das políticas sociais. A pandemia desencadeou um grave cenário epidemiológico no país e no mundo, mas as suas consequências sociais também são graves, com perspectivas de recuperação a longo prazo.

Ainda que esses recursos tenham sido importantes para a estruturação dos serviços e das ações, não podemos deixar de mencionar o fato de serem extraordinários e emergenciais, por conseguinte, a sua utilização se dá para ações pontuais em contraposição a diretrizes estruturantes do SUAS que prezam por serviços continuados e equipes de referências com vínculos trabalhistas. A base de cálculo para o repasse foram os atendimentos lançados no Relatório Mensal de Atendimento - RMAs dos serviços e no Censo SUAS dos meses/ano anterior(es), além da utilização de saldos dos recursos associados ao Índice de Gestão Descentralizada - IGD/SUAS ${ }^{7}$, cujos repasses estavam atrasados, não refletindo a demanda

\footnotetext{
${ }^{7}$ Especificamente, os recursos recebidos associados ao IGD-SUAS não podem ser destinados ao gasto com pessoal permanente, despesas relativas a pessoal concursado, seja celetista, estatutário ou mesmo comissionados, nem com
} 


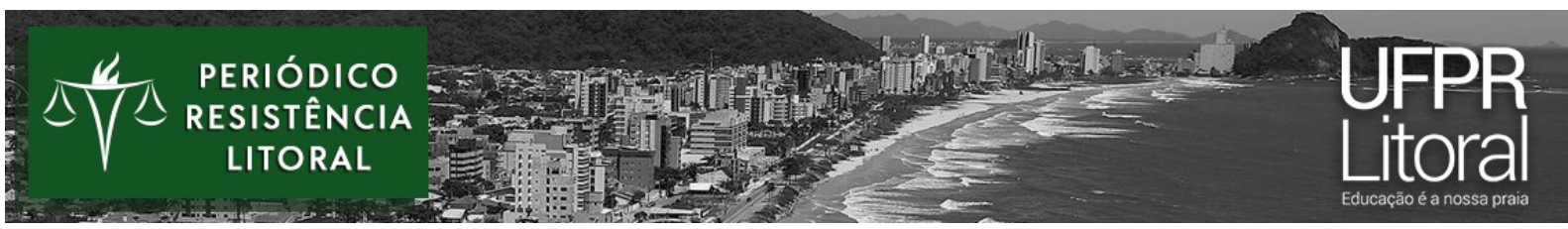

atual de atendimentos, que aumentou significativamente em todos os serviços, dado o aumento da vulnerabilidade social e a instabilidade financeira das famílias, agravados pela pandemia.

Isso porque, com a redução significativa dos recursos para o financiamento das ações, devido ao processo de restruturação e desmonte das políticas sociais no Brasil, impulsionadas pelas reformas e, principalmente, pela Emenda Constitucional n. ${ }^{\circ}$ 95/2016 (BRASIL, 2016), que congela os gastos das políticas sociais por vinte anos, escancaram-se as desproteções e evidenciam-se as desigualdades sociais na contemporaneidade, agravadas em tempos de pandemia. Com a limitação da atuação do Estado no âmbito da proteção social, a responsabilização da família, enquanto provedora e custeadora de cuidados, torna-se cada vez mais eminente e naturalizada quando diz respeito ao amparo às populações idosas e impõe novos desafio aos trabalhadores que atuam com esse segmento, inclusive, os assistentes sociais. Esse modo de gestão das políticas sociais por parte do Estado compromete um dos pilares da PAS/2004: a construção de um sistema de proteção social. É notório que vivemos

[...] um contexto de erosão significativa da proteção socioassistencial" [...] a partir da emenda constitucional n. $^{\circ}$ 95/2016, atinge igualmente as PAS-2004, acarretando insuficiência, instabilidade, incerteza e atraso dos recursos. (CAMPOS; SGORLON; TORRES, 2020, p. 141)

Além dos atos normativos referentes à organização dos serviços, observamos ainda que, no âmbito federal, foram expedidas alterações nas normativas de benefícios para a população idosa. Citamos a prorrogação da validade da Carteira do Idoso $^{8}$ (Resolução n. ${ }^{0} 03$ de 06 de agosto de 2020) e a alteração nos procedimentos para a sua emissão (Resolução n. ${ }^{\circ} 01$ de 28 de janeiro de 2021), passando a ser solicitada no CRAS e, também, via internet. No entanto, é em relação ao Benefício de Prestação Continuada - BPC, um dos mais importantes benefícios de transferência de renda para idosos e pessoas com deficiência em situação de vulnerabilidade, que encontramos uma diversificada publicação de alterações, especialmente, no tocante ao acesso e aos critérios desse benefício, conforme quadro a seguir:

QUADRO 1: NORMATIVAS REFERENTES AO BENEFÍCIO DE PRESTAÇÃO CONTINUADA

NORMATIVA

DISPOSIÇÃO

auxílios diretos aos beneficiários, que incluem a oferta de benefícios eventuais, conforme a Nota Técnica Conjunta SNAS/SGFT n. ${ }^{\circ} 01 / 2020$.

${ }^{8}$ A Carteira do Idoso é um documento que permite aos idosos que recebem até dois salários mínimos viajarem de forma gratuita ou com $50 \%$ de desconto no valor das passagens interestaduais de ônibus. 


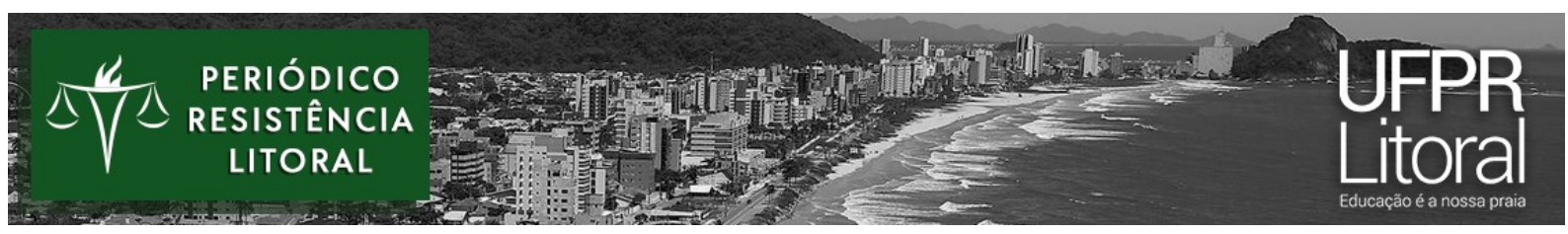

\begin{tabular}{|c|c|}
\hline $\begin{array}{l}\text { LEI N. } .^{\circ} 13.982, \text { DE } 2 \text { DE } \\
\text { ABRIL DE } 2020\end{array}$ & $\begin{array}{l}\text { Altera a Lei n. }{ }^{\circ} 8.742 \text {, de } 7 \text { de dezembro de } 1993 \text {, para dispor sobre } \\
\text { parâmetros adicionais de caracterização da situação de } \\
\text { vulnerabilidade social para fins de elegibilidade ao BPC, e estabelece } \\
\text { medidas excepcionais de proteção social a serem adotadas durante o } \\
\text { período de enfrentamento da emergência de saúde pública de } \\
\text { importância internacional decorrente do coronavírus covid-19, a que } \\
\text { se refere a Lei n. }{ }^{\circ} 13.979 \text {, de } 6 \text { de fevereiro de } 2020 \text {. }\end{array}$ \\
\hline $\begin{array}{l}\text { LEI N. }{ }^{\circ} 14.176, \text { DE } 22 \text { DE } \\
\text { JUNHO DE } 2021\end{array}$ & $\begin{array}{l}\text { Altera a Lei n. }{ }^{\circ} 8.742 \text {, de } 7 \text { de dezembro de } 1993 \text {, para estabelecer o } \\
\text { critério de renda familiar per capita para acesso ao BPC, estipular } \\
\text { parâmetros adicionais de caracterização da situação de } \\
\text { miserabilidade e de vulnerabilidade social e dispor sobre o auxílio- } \\
\text { inclusão de que trata a Lei n. }{ }^{\circ} 13.146 \text {, de } 6 \text { de julho de } 2015 \text { - Estatuto } \\
\text { da Pessoa com Deficiência; autoriza, em caráter excepcional, a } \\
\text { realização de avaliação social mediada por meio de } \\
\text { videoconferência; e dá outras providências. }\end{array}$ \\
\hline $\begin{array}{l}\text { PORTARIA CONJUNTA } \\
\text { N. } .^{3} \text {, DE } 5 \text { DE MAIO DE } \\
2020\end{array}$ & $\begin{array}{l}\text { Dispõe sobre a antecipação do BPC prevista no art. } 3^{\circ} \text { da Lei n. } \\
\text { 13.982, de } 2 \text { de abril de } 2020 .\end{array}$ \\
\hline $\begin{array}{l}\text { PORTARIA CONJUNTA } \\
\text { N. }{ }^{\circ} \text { 6, DE } 6 \text { DE AGOSTO } \\
\text { DE } 2020\end{array}$ & $\begin{array}{l}\text { Altera a Portaria Conjunta } \text { n. }^{\circ} 3 \text {, de } 5 \text { de maio de } 2020 \text {, que dispõe } \\
\text { sobre a antecipação do BPC, nos termos do art. } 3^{\circ} \text { da Lei n. }{ }^{\circ} 13.982 \text {, } \\
\text { de } 2 \text { de abril de } 2020 \text {. }\end{array}$ \\
\hline $\begin{array}{l}\text { PORTARIA CONJUNTA } \\
\text { N. }{ }^{\circ} 7, \text { DE } 14 \text { DE } \\
\text { SETEMBRO DE } 2020\end{array}$ & $\begin{array}{l}\text { Regulamenta regras e procedimentos de requerimento, concessão, } \\
\text { manutenção e revisão do BPC. }\end{array}$ \\
\hline $\begin{array}{l}\text { PORTARIA N. }{ }^{\circ} \text { 145, DE } 9 \\
\text { DE NOVEMBRO DE } 2020\end{array}$ & $\begin{array}{l}\text { Aprova Nota Técnica que esclarece posicionamento da Secretaria } \\
\text { Nacional de Assistência Social sobre a antecipação do pagamento aos } \\
\text { requerentes do BPC, decorrente do contexto de enfrentamento à } \\
\text { pandemia do novo coronavírus. }\end{array}$ \\
\hline
\end{tabular}

FONTE: Sistematização das autoras a partir da consulta aos Atos Normativos do SUAS disponível em http://aplicacoes.mds.gov.br/snas/regulacao/.

Diante dessas considerações, verificamos que o SUAS representa um sistema cujo projeto é de implantação de uma rede de proteção estatal e continuada, voltada para famílias e indivíduos em situação de vulnerabilidade social e violação de direitos, mas que vem sendo afrontado por uma política neoliberal que limita o financiamento dos serviços e dificulta o acesso da população aos benefícios e serviços socioassistenciais.

Aliado ao contexto da pandemia da covid-19, intensificam-se os desafios à população usuária das políticas sociais, dentre elas, a assistência social, o poder público, as organizações da sociedade civil e os trabalhadores que atuam nesses espaços, especialmente, nos cuidados em relação à saúde, no atendimento às demandas econômicas e sociais, especialmente, de 
sobrevivência, renda e convívio familiar, representando um dos desafios a serem superados nesse contexto de pandemia.

\section{PERSPECTIVAS E DESAFIOS PARA O ATENDIMENTO AO IDOSO NA POLÍTICA DE ASSISTÊNCIA SOCIAL}

Como mencionado anteriormente, a população idosa é constituída de grupos heterogêneos e diversos. De acordo com Torres (2020),

[...] essa heterogeneidade expressa as decorrências da desigualdade social, que se revela em insuficiência de renda, precarização da saúde, desgastes decorrentes do trabalho penoso e insalubre, entre outras questões (TORRES, 2020, p. 47)

A desigualdade social, impõe desafios cotidianos aos próprios idosos, à implementação de políticas sociais, bem como aos trabalhadores que atuam com esse segmento populacional. No contexto da pandemia de covid-19, a necessidade de acesso aos serviços, de informações sobre os benefícios socioassistenciais e de acolhida, tornou-se indispensável na garantia dos direitos dessa população.

$\mathrm{O}$ atendimento ao idoso em tempos de pandemia, na PAS (2004), tornou-se um desafio frente às normativas supracitadas que impuseram alterações e novas configurações para a realização de atendimentos presenciais, tendo em vista a necessidade da proteção aos grupos vulneráveis à contaminação do vírus, dentre os quais, a população idosa.

O/a assistente social é contratado/a para executar os serviços previamente estabelecidos nas políticas sociais. A partir dos conhecimentos apropriados por meio do seu processo formativo, analisa as contradições constitutivas da sociedade do capital e a relação desigual e hierarquizada entre as classes sociais. No trabalho desenvolvido por assistentes sociais na PAS (2004), evidenciaram-se múltiplas necessidades que passaram a se constituir como demandas de atenção aos profissionais. De forma inicial, as alterações para acesso aos benefícios eventuais de complementação da renda foram tomadas como determinantes na modificação das orientações para acessar direitos sociais básicos, por exemplo, alimentação, e das informações acerca da prestação de serviços socioassistenciais, no sentido de esclarecer e trazer noticiais fidedignas aos idosos e seus familiares, garantindo proteção e atendendo às normas sanitárias estabelecidas pelos órgãos de saúde.

Em tempos pandêmicos, é essencial aos assistentes sociais colocar em movimento os saberes acumulados sobre a realidade social, as normativas que subsidiam o ordenamento das 


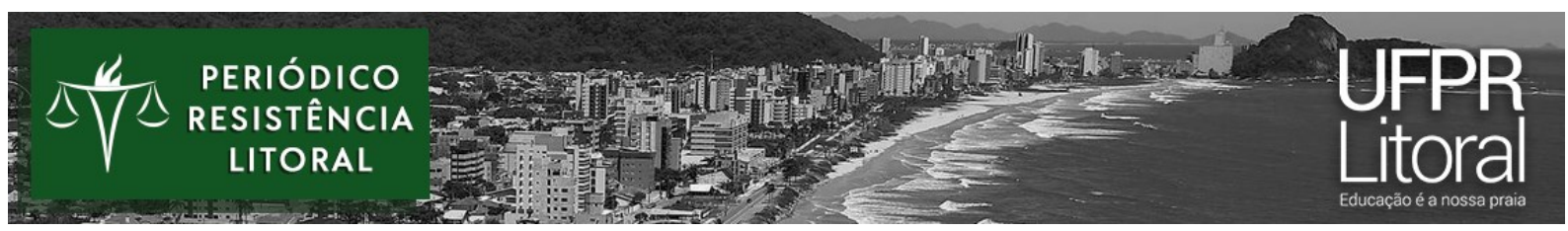

políticas sociais e as condições objetivas de vida dos trabalhadores que não reúnem condições de arcar com as suas necessidades de subsistência. Esses saberes em movimento, articulados aos fundamentos da profissão, balizam o modo como esses profissionais constroem as respostas interventivas e expressam a direção ética e política assumida pelo Serviço Social brasileiro.

É fato que o trabalho no SUAS é executado por uma equipe multiprofissional, composta por trabalhadores com formação em várias áreas do conhecimento, destacando-se, dentre eles, o/a assistente social. A complexidade de se estabelecer um sistema de proteção social requer um acervo de conhecimentos por parte dos profissionais, com vistas a contribuir também ao aprimoramento do trabalho e à construção de resultados para a política de assistência social.

Diante do cenário caótico decorrente da pandemia e a necessidade de assegurar proteção à população, os assistentes sociais e os demais trabalhadores do SUAS foram cobrados a construir, em tempo recorde, respostas emergenciais às demandas apresentadas pelos usuários.

Um dos elementos tomados como referência pelas profissionais é o evidente contexto de desproteção agravado na pandemia, determinante para a reorganização de ofertas e adequações dos serviços às novas diretrizes de atendimento, conforme os atos normativos, em curtos espaços de tempo. Outro elemento importante foi a adoção do trabalho remoto e do teletrabalho, impondo alterações nos processos de trabalho de todos os trabalhadores do SUAS. A associação entre a complexificação das demandas, as alterações nas normativas e a adaptação ao teletrabalho, provocou a necessidade de repensar o modo como o trabalho das assistentes sociais passou a ser executado.

Dois elementos são essenciais para o debate proposto. $\mathrm{O}$ primeiro diz respeito à indisponibilidade e/ou insuficiência de recursos para a realização de atividades remotas, tais como, equipamentos que não comportam a utilização de aplicativos e outras mídias sociais, compartilhamento de computadores, número de celulares insuficientes, o que provocou a necessidades de as assistentes sociais disponibilizarem seus próprios celulares e pacotes de internet para otimizar os atendimentos. É essencial destacar que, em diversos campos ocupacionais, as assistentes sociais passaram a ser responsáveis pelos equipamentos e recursos na execução do seu trabalho. Igualmente, depararam-se com desinformação ou, melhor dizendo, com a deturpação das informações acerca das medidas sanitárias, do acesso aos benefícios e serviços socioassistenciais, o que contribuiu para a necessidade de construir outras estratégias de aproximação aos usuários. 


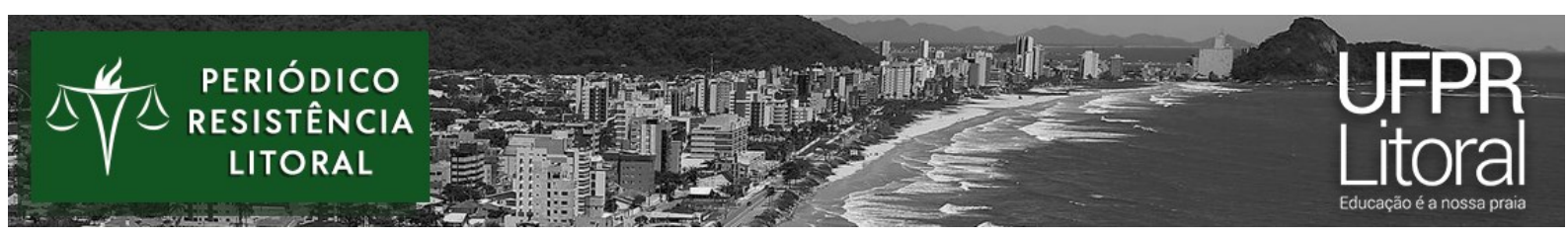

O segundo elemento se refere ao uso das Tecnologias da Informação e Comunicação TICs para otimizar a comunicação e a orientação dirigida aos usuários, com a utilização de redes sociais, aplicativos de mensagens e contatos telefônicos, incluindo as ligações por vídeo; e a articulação com a rede de serviços, via encontros em salas virtuais, para a realização de discussões de atendimento, encaminhamentos de demandas e atendimento às necessidades emergentes que a pandemia impôs.

No desenvolvimento das primeiras ações em tempos pandêmicos, as assistentes sociais identificaram que a população idosa com menor poder aquisitivo apresentaram dificuldades de acesso e no uso dessas TICs, sendo necessário viabilizar o atendimento presencial ou a visita domiciliar, a fim de a orientação e o acesso aos serviços serem efetivados.

Ressalta-se que os atendimentos presenciais foram limitados a situações urgentes e emergentes, especialmente, os decorrentes de suspeita de violência, fornecimento de alimentos e isolamento. Para idosos residentes sozinhos, por exemplo, quando necessário, os trabalhadores do SUAS realizam atendimentos assegurando as medidas sanitárias de uso de EPIs, o distanciamento entre as pessoas, entre outros. $\mathrm{O}$ atendimento domiciliar é realizado em situações nas quais o idoso apresenta graus de dependência que o impedem de tomar decisões e são impeditivos da sua mobilidade, agravada com a necessidade de se manter em casa. Nesse contexto pandêmico, o cuidado familiar foi essencial para assegurar a qualidade de vida dos idoso no tocante ao acesso à medicação, rotina de higiene, entre outras necessidades. No atendimento domiciliar, os assistentes sociais atenderam a múltiplas demandas, especialmente, de entrega de alimentos, máscaras, orientações gerais quanto ao vírus e às medidas sanitárias, orientações sobre o processo de agendamento para a vacinação, orientações aos cuidadores, a fim de facilitar a convivência diária, e a acolhida no momento de luto.

No tocante aos trabalhadores do SUAS, foi visível a diminuição do número de trabalhadores presenciais em seus locais de trabalho, uma vez que os profissionais do grupo de risco também foram colocados em trabalho remoto, alterando a dinâmica das equipes. A alteração do número de trabalhadores e a ausência de uma definição de retorno ao trabalho presencial criaram vários desafios, dentre eles, o de equacionar o volume de atendimento, a gestão dos benefícios socioassistenciais e o trabalho desenvolvido com a rede de serviços. Diante dessa questão, vários profissionais das equipes foram remanejados em suas funções. Assim, motoristas, educadores sociais, articuladores de projetos, entre outros, foram 


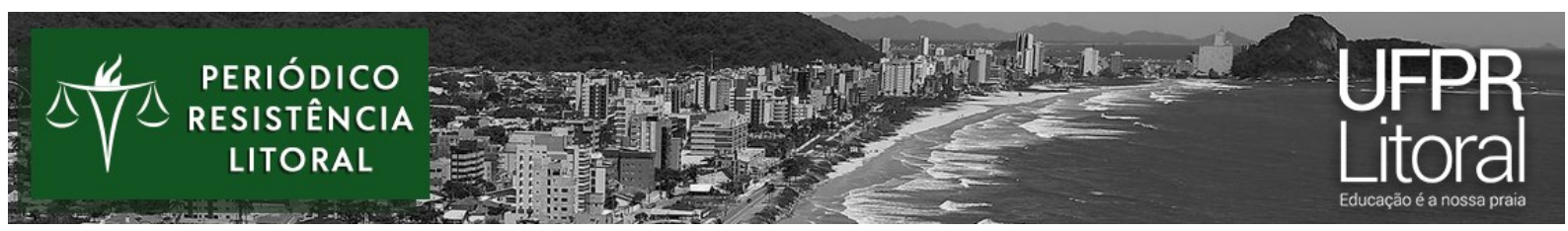

requisitados a participar no atendimento direto à população, na entrega de alimentos, apoiando as equipes técnicas.

O que se observou é a fragilização e a descontinuidade na oferta de serviços socioassistenciais, indicando uma irreparável perda no sistema de proteção social. A exiguidade do investimento público nas políticas sociais impacta na resposta interventiva elaborada pelos trabalhadores do SUAS, indicando que as referidas respostas ainda são constituídas de ações seletivas e não contemplam todos aqueles que necessitam da proteção social. Em tempos pandêmicos é visível a precarização do trabalho e o agravamento das condições de saúde dos trabalhadores. Raichelis e Arregui (2021, p. 139) afirmam que a precarização do trabalho é “"[...] uma estratégia do padrão de acumulação capitalista [...] que combina flexibilização, terceirização e informalidade do trabalho". A adoção da gestão gerencialista para a execução das políticas sociais reforça o estabelecimento de metas de atendimento e a premissa de que todos os trabalhadores podem realizar as atividades, contribuindo para a dificuldade dos assistentes sociais de identificarem os resultados do trabalho desenvolvido.

Diante desse novo cotidiano de trabalho nos equipamentos socioassistenciais, todos os trabalhadores usuários dos serviços foram diretamente afetados. Os grupos que tradicionalmente se enquadravam como público prioritário da política ficaram visivelmente expostos aos agravos da pobreza, das situações de negligência e da violência. Nesse grupo, incluem-se, além de crianças e adolescentes, as mulheres e os idosos. No tocante à velhice, Torres (2020 p. 48) afirma que “[...] a ênfase no acesso aos serviços - principalmente, aqueles associados à seguridade social [...]”, torna-se fundamental para a manutenção da vida. Assim, a desigualdade social emergente no contexto pandêmico brasileiro agravou as condições objetivas de vida dos trabalhadores, impondo desafios aos trabalhadores da política de assistência social, dentre eles, o/a assistente social.

Sendo a assistência social considerada política essencial no contexto da pandemia, o trabalho realizado pelos trabalhadores do SUAS tem se mostrado de extrema relevância. O trabalho do/a assistente social na política de assistência social caracteriza-se por intervenções que englobam abordagens individuais, familiares ou grupais, em uma perspectiva de atendimento às necessidades sociais básicas, acesso a direitos, bens e serviços socioassistenciais; e a articulação com os serviços das demais políticas, por meio de ações intersetoriais. Outro foco do trabalho são as ações junto aos movimentos sociais e as ações de 
controle social que favorecem a socialização das informações, mobilização e organização popular, essencial para a permanência dos direitos conquistados pelos trabalhadores.

Apesar de a assistência social ser um dos espaços de trabalho mais tradicionais e persistentes do assistente social (RAICHELIS, 2010), considera-se que a implantação do SUAS ampliou as possibilidades de trabalho profissional, com novos espaços, atribuições e competências necessárias aos enfrentamentos das situações que se apresentam em seu cotidiano.

A Lei de Regulamentação da profissão, ao se referir às competências dos assistentes sociais, em seu artigo $4^{\circ}$, inciso III, estabelece que o profissional deve encaminhar providências e prestar orientação social a indivíduos, grupos e à população. E, ainda, o Código de Ética, atribui como um dever do/a assistente social participar de programas de socorro à população em situação de calamidade pública, no atendimento e defesa de seus interesses e necessidades (CFESS, 1993). As normativas da profissão determinam quão grande é a responsabilidade e o compromisso profissional de assistentes sociais em momentos de crise como esse que estamos vivendo diante da pandemia. Nesse contexto, o profissional, ao prestar orientações a grupos e populações, cria diferentes estratégias de comunicação, de modo a alcançar os usuários dos serviços socioassistenciais, informando, principalmente, seus direitos e ressaltando que seu trabalho se fundamenta na perspectiva da defesa dos direitos humanos e sociais. Nesse sentido, a recuperação da prática socioeducativa tem se mostrado uma importante estratégia em defesa da vida e, no contexto de velhice, tornou-se, na pandemia, urgente e emergente.

Portanto, torna-se fundamental aos assistentes sociais evidenciarem sua capacidade de projetar, planejar e executar o trabalho profissional, embasado na apropriação dos conhecimentos que fundamentam as dimensões teórica, metodológica, ética, política e técnicooperativa que sustentam a profissão, ao mesmo tempo em que permite a análise da conjuntura e a construção de uma intervenção voltada aos interesses da classe trabalhadora.

Inclusive, um dos compromissos profissionais expressos no Código de Ética do Assistente Social é com a defesa da qualidade dos serviços prestados à população (CFESS, 1993). Sendo esse um dos princípios éticos fundamentais, o/a assistente social deve estar atento aos preceitos éticos, especialmente, quando da realização de trabalho, utilizando-se das TICs, além de dispor de condições para realizar suas atividades profissionais. Cabe aqui a atenção dos assistentes sociais às implicações éticas decorrentes do uso das TICs no atendimento aos idosos. A depender da ferramenta utilizada, o acesso às informações passa a ser de domínio público, 
tornando-se essencial que assistentes sociais pensem como as informações serão preservadas. O sentido proposto é que, ao determinar a condição do atendimento social, bem como as demais ações direcionadas a essa população, os assistentes sociais devem ter, no horizonte, a preservação do sigilo e da confidencialidade das informações, pois é o responsável pela decisão de quais dados e informações registrará na documentação técnica produzida. Ou seja, é essencial que os profissionais tenham clareza dos princípios e valores que orientam a profissão, e, nesse sentido, a preservação do sigilo e da confidencialidade está estabelecida enquanto direito e dever do profissional.

Conforme mencionado, como trabalhador do SUAS, o/a assistente social é requisitado a realizar o atendimento direto com os usuários e, no contexto pandêmico, isso implica em maior rigor com o uso de equipamentos individuais de proteção individual e coletiva, de modo a garantir a segurança aos usuários e profissionais. É nosso dever prestar atendimento à população, em tempos pandêmicos, resguardando-nos e aos idosos, o que implica em condições objetivas para realizar o trabalho profissional e uma atuação que proporcione refletir, questionar e problematizar, tal como é possibilitado o acesso e a qualidade dos serviços ofertados à população.

\section{CONSIDERAÇÕES FINAIS}

A pandemia de covid-19 expôs, ainda mais, as desigualdades e as contradições que estruturam o capitalismo, tornando visível a relação hierárquica e desigual entre as classes sociais, expressas no preconceito exacerbado contra os povos originários, os povos tradicionais, a população de pele preta e os trabalhadores pobres. É notório o recrudescimento da violência intrafamiliar e a conflituada relação intergeracional que atinge sobremaneira os idosos. Outro aspecto fundamental é a volta do Brasil ao Mapa da Fome, demonstrando que os custos sociais são incalculáveis. O Estado brasileiro, ao propor haver um dilema entre a vida e a economia, defendendo que a defesa da economia é fundamental, revela que os mandatários do Poder Executivo Federal exortam a manutenção dos interesses e da lógica predatória do capital.

Em virtude das reflexões apontadas neste artigo, podemos inferir que ser idoso na sociedade contemporânea tem sido desafiado pelo contexto das relações sociais e da convivência familiar e comunitária, mesmo dos idosos independentes. No âmbito da proteção social, as famílias são tidas como a primeira instância de cuidados dos seus idosos e, quando 
não podem exercê-los, em sua plenitude, a sociedade e o poder público devem assegurar as condições para tal. Ocorre que o contexto de reestruturação das políticas sociais, com o consequente desfinanciamento das ações, tem limitado o acesso da população aos seus direitos básicos, agravado no cenário pandêmico da covid-19. Outra evidência é a alteração no cotidiano de trabalho: a intensificação do trabalho é evidente. Diante do aumento e da complexificação das demandas, e da desregulamentação do investimento público na política de assistência social, nota-se o impacto tanto na execução do trabalho, como em seus resultados.

Diante das supracitadas normativas que passam a ordenar o trabalho desenvolvido pelos trabalhadores do SUAS, os assistentes sociais passam a gerir os benefícios socioassistenciais, muitas vezes, tomando os critérios de elegibilidade como essenciais ao acesso aos serviços, haja vista não haver recursos para atender a todos. Outra questão evidenciada é o estabelecimento de metas de atendimento incompatíveis com as condições de trabalho, quer seja pela ausência de recursos e de equipamentos, quer seja pela distância entre as condições concretas e o fim da pandemia. No tocante aos idosos, população foi e segue atingida sobremaneira pela pandemia, permanecendo como público prioritário de proteção e necessitando de ações permanentes de acompanhamento e orientação na defesa do acesso aos benefícios e serviços, bem como aos direitos previstos na legislação.

A desigualdade social estabeleceu que as condições objetivas de vida da população fossem fatalmente afetadas e o compromisso profissional estabelecido no Código de Ética foi extremamente requisitado, visando a proteção e a orientação quanto aos cuidados, bem como, muitas vezes, a viabilidade material de instrumentos de proteção, como máscaras, luvas, álcool, e o acesso a alimentação e itens essenciais para a garantia de condições mínimas de sobrevivência em tempos de pandemia. Após um ano de pandemia, visto que o aporte do poder público e as possibilidades de ampliação de recursos foram realizados de forma provisória com o orçamento de guerra, identifica-se que o investimento foi insuficiente para responder as demandas apresentadas.

Portanto, consideramos que, embora a Constituição Federal de 1988 considere o idoso como sujeito de direitos, é necessário discutir o acesso aos direitos, uma vez que se encontram ameaçados pelo contexto pandêmico e precário investimento do poder público.

\section{REFERÊNCIAS BIBLIOGRÁFICAS}

BEAUVOIR, Simone de. A velhice. 2 ed. Rio de Janeiro: Nova Fronteira, 2018. 599 p. 


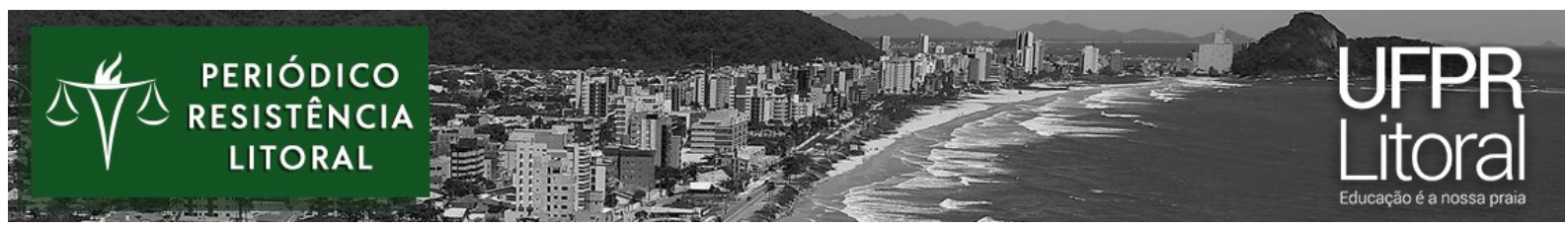

BRASIL. Lei n. ${ }^{\circ} 10.741$, de $1^{\circ}$ de outubro de 2003. Dispõe sobre o Estatuto do Idoso e dá outras providências. Brasília: Presidência da República Casa Civil Subchefia para Assuntos Jurídicos 1993. Disponível em http://www.planalto.gov.br/ccivil_03/leis/2003/110.741.htm Acesso em 20 abr. 2020.

BRASIL, Código de ética do/a assistente social. Lei n. ${ }^{\circ}$ 8.662/93 de regulamentação da profissão. 10a . ed. rev. e atual. - [Brasília]: Conselho Federal de Serviço Social, [2012].

BRASIL. Constituição da República Federativa do Brasil. Brasília, 1988.

BRASIL. Ministério da Saúde. Secretaria de Atenção a Saúde. Departamento de Atenção Básica. Envelhecimento e Saúde da Pessoa Idosa/Ministério da Saúde. Secretaria de Atenção à Saúde. Departamento de Atenção Básica. Brasília: Ministério da Saúde, 2006. 192p. (série A. Normas e Manuais Técnicos) (Caderno de Atenção Básica, n.19).

$\begin{array}{ccccc}\text {. } & \text { Estatuto do } & \text { Idoso. } & \text { Disponível }\end{array}$

https://www.planalto.gov.br/ccivil_03/Leis/2003/L10.741.htm>. Acessado em 21/04/2021.

. Política Nacional de Assistência Social. Brasília: Imprensa Nacional, 2004.

Decreto n. ${ }^{0} 10.282$ de 20 de março de 2020. Disponível em

https://www.in.gov.br/en/web/dou/-/republicacao-249098206. Acessado em 07/09/2020 as 17h35m.

Portaria n. ${ }^{\circ} 337$ de 24 de março de 2020. Disponível em http://www.in.gov.br/en/web/dou/-/portaria-n-337-de-24-de-marco-de-2020-249619485. Acessado em 04/06/2020.

Portaria n. 369 de 29 de abril de 2020. Disponível em $<$ https://www.in.gov.br/web/dou//portaria-n-369-de-29-de-abril-de-2020-254678622>. Acessada em 07/09/2020 as 19hs.

. Portaria n. 378 de 07 de maio de 2020. Disponível em https://www.in.gov.br/en/web/dou//portaria-n-378-de-7-de-maio-de-2020-255870366. Acessado em 02/08/2021 as 9hs.

. Portaria Conjunta n. ${ }^{0} 01$ de 02 de abril de 2020. Disponível em $<$

https://covid.inteligov.com.br/publicacoes/5359-portaria-conjunta-n-1-de-2-de-abril-de-2020>. Acessado em 02/08/2020 as $10 \mathrm{~h} 32 \mathrm{~m}$.

CAMARANO, Ana Amélia, KANSO, Solange; MELLO, Juliana Leitão de. Características Sociodemográficas da População Idosa. In: CAMARANO, Ana Amélia. (Org.) Os novos idosos brasileiros, muito além dos 60? Rio de Janeiro: IPEA, 2004. p.25-73.

CAMPOS, Soraya de Paula Garcia; SGORLON, Claudiana Tavares da Silva; TORRES, Mabel Mascarenhas. O trabalho da/o assistente social na Política de Assistência Social em tempos de pandemia. In: PONTES, Reinaldo Nobre; VOLPATO, Adriéli; AMARO, Sarita (org.). Serviço Social e Pandemia COVID-19: realidade, desafios e práxis. Porto Alegre, RS: Nova Práxis Editorial, 2020, p. 135-160 


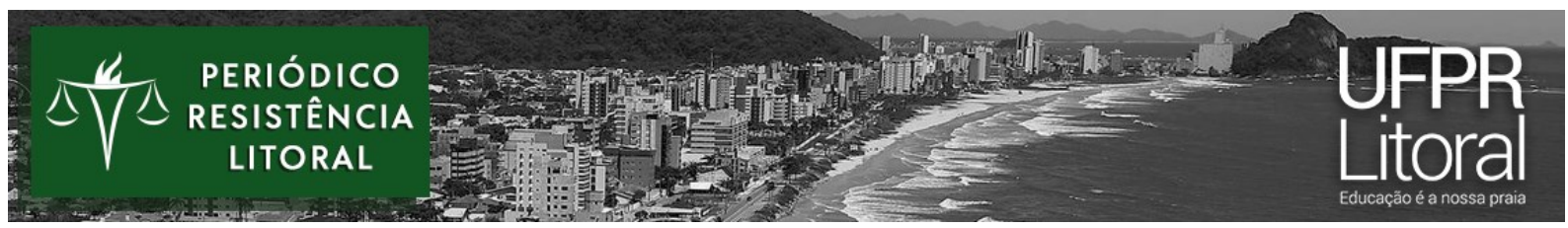

CONSELHO ESTADUAL DOS DIREITOS DO IDOSO, (CEDI). O idoso no Paraná. Disponível em: http://www.cedi.pr.gov.br/Pagina/O-Idoso-no-Parana. Acesso em 04 de agosto de 2021

COSTA, Joice Souza. Envelhecimento e Lutas de Classes: as Mobilizações Políticas dos Velhos na Cena Brasileira. In: TEIXEIRA, Solange Maria (org.). Envelhecimento na Sociabilidade do Capital. Campinas: Papel Social, 2017, p.141-158.

COSTA, Joice Souza. Precariedades do envelhecer e a garantia de direitos na tessitura do capital. In: TEIXEIRA, Solange Maria; CAMPELO E PAIVA, Sálvea de Oliveira; SOARES, Nanci (org.). Envelhecimento e políticas sociais em contexto de crises e contrarreformas. Curitiba, Pr: CRV, 2019, p. 95-114.

INSTITUTO BRASILEIRO DE GEOGRAFIA E ESTATISTICA (IBGE). Disponível em: https://censo2021.ibge.gov.br/2012-agencia-de-noticias/noticias/29505-expectativa-de-vidados-brasileiros-aumenta-3-meses-e-chega-a-76-6-anos-em-2019.html. Acessado em 16 de abril de 2021 .

RAICHELIS, Raquel. Intervenção profissional do assistente social e as condições de trabalho no SUAS. In: Revista Serviço Social e Sociedade. São Paulo, Cortez, n. ${ }^{\circ}$ 104, p. 750-772, outubro/dezembro, 2010.

RAICHELIS, Raquel; ARREGUI, Carola C. O trabalho no fio da navalha: nova morfologia no Serviço Social em tempos de devastação e pandemia. In: Revista Serviço Social e Sociedade. São Paulo: Cortez, 2021, p. 134-152. Disponível em: https://www.scielo.br/pdf/sssoc/n140/0101-6628-sssoc-140-0134.pdf. Acesso: 21 junho 2021.

SILVEIRA, Jucimeri Isolda. Assistência social em risco: conservadorismo e luta social por direitos. In: Revista Serviço Social e Sociedade, São Paulo, n. 130, p. 487-506, set./dez. 2017, p. 487-506

TEIXEIRA, Maria Solange. Envelhecimento do trabalhador na Sociedade Capitalista. In: TEIXEIRA, Solange Maria (org.). Envelhecimento na Sociabilidade do Capital. Campinas: Papel Social, 2017.p.31-51.

TORRES, Mabel Mascarenhas. (2020). O trabalho do assistente social com pessoas idosas: competências e demandas em debate. In: TEIXEIRA, S. M (org.). Serviço Social e Envelhecimento. Teresina, PI: EDUFPI, p. 46-73.

YASBEK, Maria Carmelita. Proteção Social e crise no Brasil contemporâneo. In: RAICHELIS, Raquel; VICENTE, Damaris; ALBUQUERQUE, Valéria. A nova morfologia do trabalho no Serviço Social. São Paulo: Ed. Cortez, 2018, p. 88-107. 